\title{
The impact of a new exercise facility on physical activity at the community level: a non-randomized panel study in Japan
}

\author{
Akio Kubota ${ }^{1,2^{*}}$, Munehiro Matsushita ${ }^{1}$, Ben J. Smith ${ }^{3,4}$, Takemi Sugiyama ${ }^{2,5}$ and Takashi Arao ${ }^{6}$
}

\begin{abstract}
Background: Considering that building a sports facility is a major investment to promote population health, it is important to understand whether it is effective in increasing the level of physical activity (PA) in the community. This study examined the impact of building a new multipurpose exercise facility on community-level PA in Japan.

Methods: This non-randomised panel study compared two sites: an intervention site where a new exercise facility was built (opened after baseline data collection) and a control site where there was no such additional exercise facility. From each site, 3200 adult residents (aged 30-74 years) were randomly selected at baseline (2013) and at follow-up (2015). The number of participants retained for analysis was 845 at baseline and 924 at follow-up for the intervention site, and 821 at baseline and 1018 at follow-up for the control site. The outcomes were participants' self-reported PA, perceived availability of PA facilities, awareness of others being active, and willingness to engage in PA. We examined the interaction terms between the sites and time of measurement in regression analyses to examine whether the magnitude of change from baseline to follow-up differed between the two sites.
\end{abstract}

Results: The changes in the proportion of participants meeting the PA guideline and those engaging in moderateto-vigorous intensity PA were not significantly different between the intervention and control sites. The intervention site had a greater increase in the proportion of participants who were aware of PA facilities from baseline to followup than in the control site. The odds ratio for awareness of others being active approached significance, suggesting that there was a tendency at the intervention site towards a greater increase in the proportion of participants who noticed physically active people.

Conclusions: This study did not find community-level increases in PA after the construction of the exercise facility. However, a significant improvement in the awareness of PA facilities was observed in the intervention site. A sustained community-level effort to promote PA, possibly including social components, and a further tracking of residents' PA are needed to take a full advantage of the new exercise facility and to assess its long-term impact.

Trial registration: UMIN-CTR UMIN000034116 (retrospectively registered: 13 September 2018).

Keywords: Built environment, Sports facility, Community wide intervention

\footnotetext{
* Correspondence: ka092000@tsc.u-tokai.ac.jp

${ }^{1}$ School of Physical Education, Tokai University, 4-1-1 Kitakaname,

Hiratsuka-shi, Kanagawa 259-1292, Japan

${ }^{2}$ Mary Mackillop Institute for Health Research, Australian Catholic University,

215 Spring St, Melbourne, VIC 3000, Australia

Full list of author information is available at the end of the article
}

(c) The Author(s). 2019 Open Access This article is distributed under the terms of the Creative Commons Attribution 4.0 International License (http://creativecommons.org/licenses/by/4.0/), which permits unrestricted use, distribution, and reproduction in any medium, provided you give appropriate credit to the original author(s) and the source, provide a link to the Creative Commons license, and indicate if changes were made. The Creative Commons Public Domain Dedication waiver (http://creativecommons.org/publicdomain/zero/1.0/) applies to the data made available in this article, unless otherwise stated. 


\section{Background}

Regular physical activity (PA) confers a range of health benefits for adults, including reduced risk of developing heart disease, stroke, type 2 diabetes, and some cancers [1]. Despite public health efforts to promote PA, low levels of PA among adults are reported in many countries [2]. In Japan, only $36 \%$ of men and $29 \%$ of women had a physical activity habit (engaging in at least $30 \mathrm{~min}$ of physical activity twice a week for the last 12 months) in 2017, and the prevalence has been stable for the last 10 years [3]. Increasing population-level PA is thus a public health priority. Many PA promotion programs that have been implemented tend to focus on individual motivation to exercise, but such approaches are known to be less successful in sustaining long-term behavioral changes [4]. It is now recognized that strategies focusing only on individuals are unlikely to be sufficient to increase PA at the population level [5]. To promote PA more effectively, the ecological model of health behavior is increasingly being adopted to guide PA interventions [6]. The ecological model posits that factors at multiple levels (individual, social/community, environmental, and policy) influence individual behaviors and that interventions addressing multi-level influences are more effective [7]. A Cochrane review on community-wide interventions to increase PA also supports the importance of environmental components [8]. An important principle of the ecological model is to make participation in PA easy and accessible through various means, such as providing social support, removing barriers, and creating more opportunities to be active.

Exercise and recreational facilities where near-by residents can engage in a range of physical activities can be an important community resource to promote PA. A review of recreational environments and PA found that outdoor recreational facilities such as parks and trails are associated with residents' PA, but most studies were cross-sectional in design [9]. For instance, better access to sports facilities was found associated with a greater amount of physical activity in Korean adults [10]. A Danish study using GPS and accelerometer also found that having sports facilities nearby (within $800 \mathrm{~m}$ from home) was associated with a longer duration of moderate-to-vigorous PA [11]. There are some natural experimental studies examining the impact of improving PA facilities. An Australian study examining the impact of playground refurbishment found increased visitors and active users after restoration [12]. Similarly, a study on park renovation in the U.S. found increased visitation and more energy expenditure by park visitors after park improvement [13]. An observational cohort study in Finland has shown that participants moving to areas where access to sports facilities was poorer (increased distance to and decreased number of them) decreased their PA levels in comparison to before the move [14]. However, a recent systematic review of natural experiments has reported that research has not yet examined the impact of a new exercise facility on residents' PA [15]. Considering that building a sports facility is a major investment to promote community health, it is important to understand whether it is effective in increasing the level of PA in the community. This study examined the impact of a newly constructed multipurpose exercise facility on community-level PA, perceived availability of PA facilities, awareness of others being active, and willingness to engage in PA in Japan. A focus of this study was on mid-to-older aged adults, who can particularly benefit from additional PA, given that their daily activity levels are lower compared to younger adults [16].

\section{Methods}

\section{Study design and settings}

This study was a non-randomized panel study, in which repeated cross-sectional data were collected from different population samples at baseline and follow-up in an intervention and a control site. The intervention site was Nagaizumi, Shizuoka Prefecture (Population: 41,912; percentage of population aged $\geq 65$ years: $19 \%$, as of April 2013). The control site was Oiso in an adjacent prefecture (Population: 32,625; percentage of population aged $\geq 65$ years: $29 \%$, as of April 2013). The control site was chosen to obtain data from a locality where the population size, geography, and climate were comparable to those of the intervention site and where no major exercise facility development or PA promotion activities were expected to take place during the study period. Since the road distance between the two sites is over $50 \mathrm{~km}$ and they are in different prefectures, people in the control site were unlikely to be affected by activities in the intervention site.

\section{Study protocol}

Complete details of the trial protocol based on the Transparent Reporting of Evaluation with Nonrandomized Designs statements have been published elsewhere [17]. In March 2013, 3200 adult residents (aged 30-74 years) were randomly selected in each site from the registry of residential addresses. Individuals were chosen from lists of residents that were classified by age (30-39, 40-49, 50-59, and 60-74 years) and gender. This age group (30-74 years) was chosen as they are known to have a greater risk of developing chronic diseases [18]. Individuals who were selected received a postal invitation to take part in this study and those who agreed to participate received a survey questionnaire. There was no incentive to participate in this study. The baseline survey was returned in April 2013 by 1107 participants in the intervention site (response rate $=35 \%$ ) 
and by 1125 participants in the control site (response rate $=35 \%$ ). The intervention (detailed below) began in August 2013. In January 2015, participants were randomly recruited again. The follow-up survey was returned in February 2015 by 1210 participants in the intervention site (response rate $=38 \%$ ) and by 1121 participants in the control site (response rate $=35 \%$ ). Figure 1 illustrates the process of participants' recruitment and data collection.

\section{Intervention}

The intervention aimed to promote PA for all residents living in the intervention site. The primary intervention was the construction of a new multipurpose exercise facility, the Nagaizumi Health Promotion Center (NHPC). The NHPC, which opened in August 2013, includes indoor facilities $(25 \mathrm{~m}$ pool, $170 \mathrm{~m}$ walking trail, multi-purpose gym, and group exercise rooms) and outdoor facilities (multi-purpose athletic field, $875 \mathrm{~m}$ walking trail, and park). All residents of Nagaizumi could use facilities in the NHPC for a small fee (e.g., the use of multi-purpose gym: US\$1).

Two months after the opening of the NHPC, the health promotion division of Nagaizumi launched a "Healthy Mileage" reward program. This incentive program, originally developed by the prefectural health promotion office, sought to encourage people to engage in healthy behaviors including PA. All residents of the town were invited to take part in the program. Entrants self-reported whether they met various goals specified in the program, such as "did exercise/sports", "used stairs rather than an elevator", and "walked/cycled instead of driving". A point (an official stamp) was given to each goal achieved at town facilities including the NHPC. The points that residents earned through this scheme could be used to pay for entrance to the NHPC or to receive discounts at local grocery stores.

No special PA promotion program was implemented in the control (Oiso) site during the study period. The NHPC is not easily accessible from Oiso. However, the health promotion division of Oiso provided routine promotion activities including health education classes and health promotion events.

\section{Measures}

The primary outcome was participants' self-reported PA. It was measured at baseline and follow-up using the Japanese version of the International Physical Activity Questionnaire Short-Form (IPAQ). The IPAQ was a selfadministered questionnaire in which participants were asked to report time spent engaging in various intensities

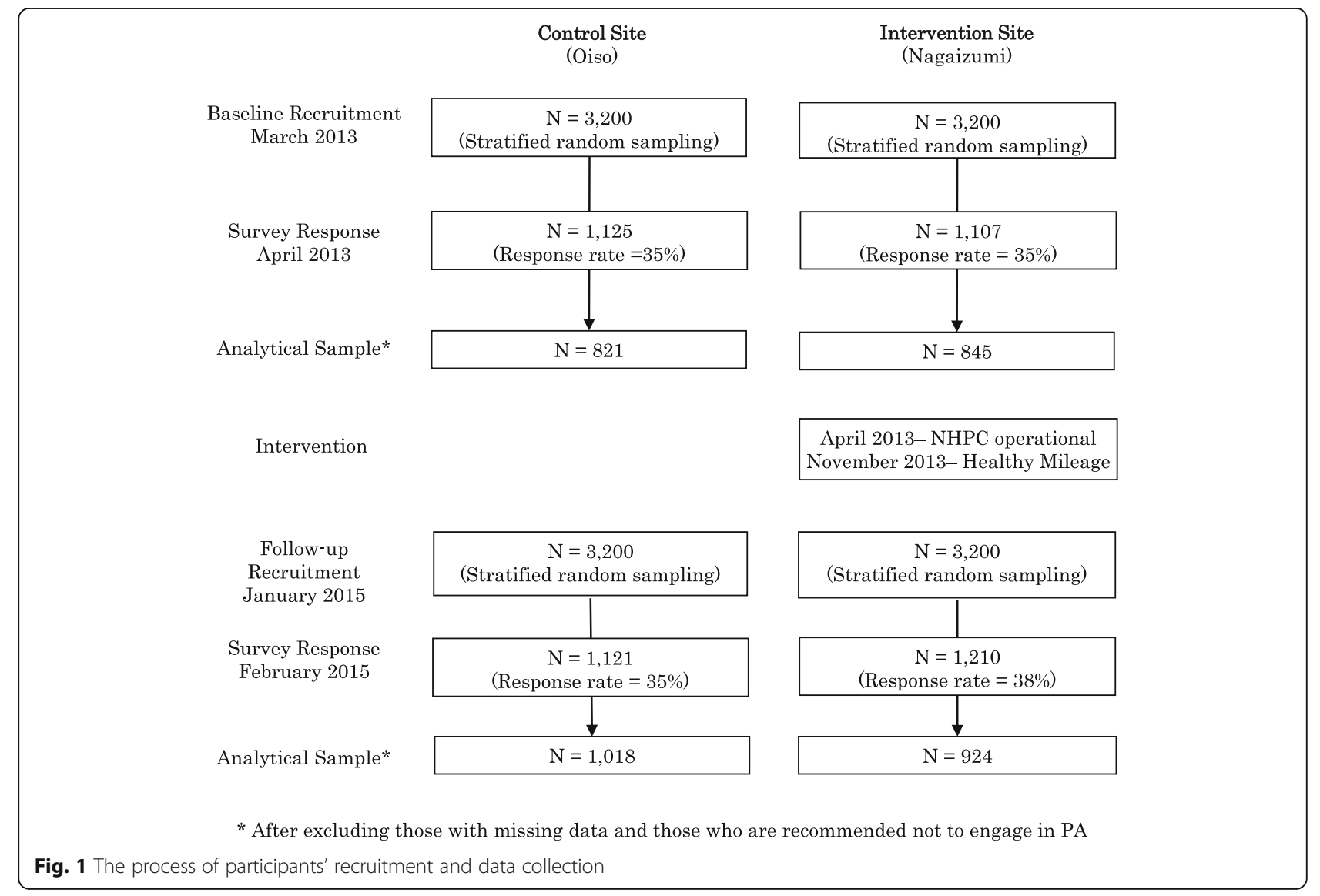


of PA over the preceding 7 days. The Japanese version has been shown to have acceptable validity and reliability [19]. Total weekly energy expenditure expressed in metabolic equivalent (MET.hour/week) was calculated following the IPAQ protocol (including truncation of excessive physical activity). Since the distribution of energy expenditure was highly skewed, categorical measures were used as PA outcomes. One PA outcome was whether or not participants met the Japanese PA guideline (total energy expenditure $\geq 23$ MET.hour/week) [20]. The other was whether participants engaged in moderate-to-vigorous intensity physical activity (MVPA, not including walking). This measure allowed us to examine whether the NHPC contributed to reducing the number of people who are totally inactive.

The secondary outcomes were perceptual and motivational factors. Perceived availability of PA facilities, awareness of others being active, and willingness to engage in PA were assessed using the following items: 1) My neighborhood has several free or low-cost recreation facilities, such as parks, walking trails, bike paths, recreation centers, playgrounds, and public swimming pools; 2) I see many people being physically active in my neighborhood; and 3) How willing are you to engage in PA? The response format ranged from 1 (strongly disagree) to 4 (strongly agree) for the first two items, and from 1 (not at all) to 4 (much) for the third item. Participant's response for each item was dichotomized into 0 (response 1 and 2) and 1 (response 3 and 4), with the latter indicating availability of PA facilities, being aware of others engaging in PA, and being willing to engage in PA.

The demographic information collected from participants included gender, age, education level $(12+$ years of education or less), marital status (single or couple), employment status (working or not), body mass index (BMI) calculated from self-reported weight and height $\left(\mathrm{kg} / \mathrm{m}^{2}\right)$, and self-rated health status (4-point scale ranging from bad to good). Participants also self-reported their overall health status on a 4-point scale, in response to the question "Overall, how would you rate your health?". The response was dichotomized into bad health (scores 1 and 2) and good health (scores 3 and 4). In addition, participants were asked whether they were told by a doctor not to engage in PA to exclude those who were unable to conduct any PA. In addition, participants were asked whether they were told by a doctor not to engage in PA to exclude those who were unable to conduct any PA.

\section{Statistical analyses}

To evaluate the effectiveness of the intervention, the changes in the outcomes from baseline to follow-up were compared between the intervention and control sites, following previous studies with the same panel design $[21,22]$. The outcomes were compared using chi- square test for unadjusted analyses and logistic regression for adjusted analyses. To examine whether the magnitude of change differed between the intervention and control sites, we used the interaction term between the sites and the time of measurement (baseline or followup). The coefficient for the interaction term indicated to what extent the intervention site "improved" in each outcome from baseline to follow-up relative to the control site [22]. These models adjusted for baseline gender, age, education level, marital status, employment status, BMI, and self-rated health. In addition, we conducted analyses stratified by gender and by age (30-59 years and 60-74 years) to check whether the intervention worked differently for sub-groups. Analyses were conducted using IBM SPSS version 24 (IBM, Armonk, NY). Statistical significance was set at $p<0.05$.

\section{Results}

Table 1 shows the baseline and follow-up characteristics of participants in the intervention and control sites. After excluding participants who were told by a doctor not to engage in PA and those who had missing data in the outcomes or demographic variables, the number of participants retained for analysis was 821 for the intervention site and 845 for the control site at baseline, and 1018 for the intervention site and 924 for the control site at follow-up. The number of participants at baseline was smaller than that at follow-up. This was mainly because the baseline survey was unclear about how to answer the gender question. This problem was rectified in the follow-up survey. At baseline, participants in the intervention site were more likely to have lower educational attainment and to be working, compared to those in the control site. At follow-up, participants in the intervention site were more likely to be younger, to have lower educational attainment, to live alone, and to be working, compared to those in the control site.

During the study period, the NHPC was used by 275 persons/day in 2013 and 443 person/day in 2014. The NHPC organized two major promotion events per year, attracting in total 1100 persons in 2013 and 600 persons in 2014 (in addition to daily users of the NHPC). The Healthy Mileage program usage was 311 times in 2013 (less than once per day) and 986 times in 2014 (2.7 times/day).

Table 2 shows the change in each outcome measure from baseline to follow-up for the intervention and control sites, and the adjusted differences between the sites at baseline and follow-up. Odds ratios greater than 1 indicate that the corresponding figure is larger in the intervention site than in the control site. The proportion of participants meeting the PA guideline decreased slightly from baseline to follow-up both in the intervention site and the control site. The same was true for the 
Table 1 Characteristics of participants in the intervention and control sites at baseline and follow-up

\begin{tabular}{|c|c|c|c|c|c|c|}
\hline \multirow[t]{2}{*}{ Items } & \multicolumn{2}{|l|}{ Baseline } & \multirow[t]{2}{*}{$P$} & \multicolumn{2}{|l|}{ Follow-up } & \multirow[t]{2}{*}{$P$} \\
\hline & Intervention site & Control site & & Intervention site & Control site & \\
\hline N & 821 & 845 & - & 1018 & 924 & - \\
\hline Age, Mean \pm SD & $52.9 \pm 12.5$ & $53.1 \pm 12.5$ & 0.68 & $52.1 \pm 12.3$ & $53.2 \pm 12.4$ & 0.04 \\
\hline Gender, \% Men & 40.9 & 42.0 & 0.65 & 43.3 & 46.0 & 0.24 \\
\hline Education level, $\%>12$ years & 51.8 & 65.1 & $<0.001$ & 55.8 & 67.6 & $<0.001$ \\
\hline Marital status, \% Single & 7.6 & 5.9 & 0.18 & 9.1 & 6.1 & 0.01 \\
\hline Employment status, \% Working & 65.4 & 58.9 & 0.01 & 69.7 & 65.2 & 0.03 \\
\hline BMI, Mean \pm SD & $22.3 \pm 3.3$ & $22.2 \pm 3.1$ & 0.64 & $22.2 \pm 3.2$ & $22.3 \pm 3.1$ & 0.68 \\
\hline Self-rated health, $\%$ Good $^{\text {a }}$ & 88.6 & 89.6 & 0.50 & 87.7 & 88.4 & 0.64 \\
\hline
\end{tabular}

${ }^{a}$ Scores 3 and 4 on a scale ranging from 1 (bad health) to 4 (good health)

percentage of people who engaged in MVPA. This may be because the follow-up survey was conducted in February, which was slightly colder than April when the baseline survey was conducted. The intervention site had a marginally lower proportion of participants meeting the PA guideline than the control site at baseline, but it was not significantly different at follow-up. The two sites did not differ in the percentage of those who engaged in MVPA at baseline or follow-up. The proportion of those who knew of PA facilities nearby was significantly higher in the intervention site than the control site both at baseline and follow-up. The proportion of those who were aware of others being active was significantly lower in the intervention site than the control site at baseline, but it was not significantly different at follow-up. The intervention and control sites did not differ in participants' willingness to engage in PA both at baseline and at follow-up.

Table 3 shows the regression coefficients of the interaction terms between the sites and the time of measurement, which can be interpreted as the adjusted differences in the change (from baseline to follow-up) between the intervention and control sites. Odds ratios greater than 1 denote that the intervention site had a greater improvement in the outcome of interest than did the control site. The changes in the proportion of participants meeting the PA guideline and those engaging in MVPA were not significantly different between the intervention and control sites. The intervention site had a greater increase in the proportion of participants who were aware of PA facilities from baseline to follow-up than in the control site. The odds ratio for participants' awareness of others being active approached significance $(p=0.09)$, suggesting there was a tendency at the intervention site towards a greater increase in the proportion of participants who noticed physically active people from baseline to follow-up. There was no significant difference between the intervention and control sites in terms of the changes in participants' willingness to engage in PA. The results of analyses stratified by gender and by age (30-59 years and 60-74 years) are shown (see Additional file 1). Gender-specific analyses found that more women in the intervention site became aware of PA facilities at follow-up than did those in the control

Table 2 The adjusted differences between the intervention and control sites at baseline and follow-up

\begin{tabular}{|c|c|c|c|c|c|c|c|c|}
\hline \multirow[t]{2}{*}{ Items } & \multicolumn{3}{|c|}{ Intervention site } & \multicolumn{3}{|c|}{ Control site } & \multicolumn{2}{|c|}{$\begin{array}{l}\text { Adjusted differences between the } \\
\text { intervention and control sites: } \\
\text { Odds ratios }(95 \% \mathrm{Cl})^{\mathrm{b}}\end{array}$} \\
\hline & $\begin{array}{l}\text { Baseline } \\
n=821\end{array}$ & $\begin{array}{l}\text { Follow-up } \\
n=1018\end{array}$ & $\begin{array}{l}\text { Change } \\
\text { a }\end{array}$ & $\begin{array}{l}\text { Baseline } \\
n=845\end{array}$ & $\begin{array}{l}\text { Follow-up } \\
n=924\end{array}$ & $\begin{array}{l}\text { Change } \\
\text { a }\end{array}$ & Baseline & Follow-up \\
\hline$\%$ of those who met the PA guideline & 20.2 & 18.5 & -1.7 & 23.2 & 21.1 & -2.1 & $\begin{array}{l}0.80 \\
(0.63,1.01) \dagger\end{array}$ & $0.83(0.66,1.04)$ \\
\hline$\%$ of those who engaged in MVPA & 42.6 & 39.6 & -3.0 & 44.5 & 43.3 & -1.2 & $0.95(0.78,1.16)$ & $0.88(0.73,1.05)$ \\
\hline $\begin{array}{l}\% \text { of those who perceived availability of PA } \\
\text { facilities }\end{array}$ & 76.4 & 81.2 & 4.8 & 68.2 & 67.0 & -1.2 & $\begin{array}{l}1.59 \\
(1.28,1.99)^{* *}\end{array}$ & $\begin{array}{l}2.34 \\
(1.89,2.90)^{* *}\end{array}$ \\
\hline $\begin{array}{l}\% \text { of those who were aware of others being } \\
\text { active }\end{array}$ & 85.7 & 87.8 & 2.1 & 89.8 & 88.4 & -1.4 & $0.71(0.52,0.96)^{*}$ & $1.02(0.77,1.35)$ \\
\hline$\%$ of those who were willing to engage in PA & 87.0 & 85.0 & -2.0 & 87.5 & 86.6 & -0.9 & $1.04(0.77,1.39)$ & $0.94(0.72,1.22)$ \\
\hline
\end{tabular}

$+p<0.1,{ }^{*} p<0.05,{ }^{* *} p<0.01$

${ }^{\text {a }}$ Follow-up minus baseline

${ }^{\mathrm{b}}$ Analyses adjusted for gender, age, education level, marital status, employment status, BMI, and self-rated health (reference: control site) 
Table 3 Differences in outcome changes from baseline to follow-up between the intervention and control sites

\begin{tabular}{lll}
\hline Items & Odds ratios for the interaction term between the site and time ${ }^{{ }^{a}}$ & $P$ \\
\hline \% of those who met the PA guideline & $1.01(0.86,1.19)$ & 0.91 \\
\% of those who engaged in MVPA & $1.80 .84,1.09)$ & 0.51 \\
$\%$ of those who perceived availability of PA facilities & $1.19(0.97,1.46)$ & 0.02 \\
$\%$ of those who were aware of others being active & $0.96(0.79,1.17)$ & 0.09 \\
$\%$ of those who were willing to engage in PA & 0.69 \\
\hline a
\end{tabular}

site. No significant differences were observed for men. Age-specific analyses found a greater increase in the proportion of older participants (60-74 years) who were aware of PA facilities and aware of others being active from baseline to follow-up in the intervention site, relative to the control site. No significant differences were observed for younger adults (30-59 years).

\section{Discussion}

This study assessed the impact of building a new multipurpose exercise facility on a community-level PA. Although there have been some natural experimental studies investigating the effect of park improvements $[12,13]$, no research to date appears to have examined whether building a new exercise facility increases PA at the community level [15]. During the two-year study period, the intervention site, where the new exercise facility was built, did not show a significant increase in the PA measures relative to the control site. Similar non-significant changes in PA have been observed in other studies involving community-wide interventions [21, 23-25]. A review of community-based PA interventions also reports inconsistent findings with regard to their effects in increasing PA [8].

A potential reason for not finding significant increases in PA measures, despite a relatively large number of NHPC users, is that the new exercise facility may have attracted people who were already active elsewhere, rather than encouraging non-active people to initiate PA. The ecological model holds that multi-level interventions (involving individual, social, and environmental influence) are more effective, than single-level interventions [6]. A natural experiment examining park renovation found that modifications to the physical improvement alone are not enough to increase PA; programs that facilitate people to be active are also needed $[26,27]$. Although the intervention examined in this study was multi-level, involving individual (incentive by the Healthy Mileage program) and environmental (the NHPC) factors, the uptake of the Healthy Mileage program was very low. A stronger incentive program that would reach a broader population may have been needed to take advantage of the new exercise facility. A social element was also lacking in the intervention implemented in this study. Additional strategies, such as involving existing community groups, working with community champions, and the use of social media, may have improved the reach and effectiveness of the intervention.

The study found that more people in the intervention site became aware of PA facilities at follow-up, compared with those in the control site, which was potentially due to media coverage of the NHPC. Gender- and age-specific analyses found that this was particularly the case with women and older adults. It can be argued that more women and older adults became aware of the facilities as they possibly spent longer time in their neighborhoods and were more exposed to local information. Given that women and older adults tend to be less active compared to their counterparts [28], the increased awareness of PA opportunities can be used as a foundation for increasing PA among them in future intervention efforts.

The study also found a marginally significant increase in the proportion of people who were aware of others being active in the intervention site. However, research appears to be mixed in the role of recognizing other people being active as a correlate of PA [29-31]. Considering that participants' willingness to engage in PA did not improve in the intervention site, the construction of the new exercise facility may not have been strong enough to change residents' attitudes towards participating in PA. It can be also argued that a two-year study period was not long enough to change residents' motivational factors relevant to PA. The review on community-based PA interventions mentioned above reported that the median intervention period of the studies identified was 3 years (range: 1 to 7 years) [8]. Continuing promotion efforts (and long-term observation) may be needed to achieve a shift in the stages of PA [32].

A strength of this study was that we collected PA data before and after the construction of a new exercise facility, with comparable PA data from the control site where no special PA promotion was conducted during the study period. This study used a panel design, where data were collected at baseline and follow-up, rather than conducting a cohort study. This methodological decision was made to assess PA participation at the community 
level consistently at baseline and follow-up. Although participants recruited at baseline and at follow-up were somewhat different in socio-demographic characteristics (Table 1), random sampling at both time points can reduce selection bias. This is potentially an advantage of a panel design in contrast to a cohort design, which could introduce systematic attrition bias at follow-up. A study limitation was the use of self-reported PA measures, which may be subject to recall error and desirability bias. An objective PA measure using activity monitors is needed for future research to produce more robust evidence. Another issue was that the baseline and follow-up data were collected in different months (April for baseline, February for follow-up) due to a funding requirement to end the project before March 2015. However, we do not think this is a major limitation as the study compared the intervention and control sites in their changes in physical activity (not simply the magnitude of change from baseline to follow-up). The study did not consider the effect of existing facilities. Although the NHPC was the first multipurpose exercise facility in Nagaizumi, it is unknown whether the existing recreational facilities were meeting the residents' demands for physical activity. It is also unknown whether new exercise facilities opened in adjacent localities or existing facilities were renovated during the study period, which may have influenced the results. The study was conducted in a regional city with a small population. The introduction of a new exercise facility in an urban context may produce different effects. We were unable to assess the impact of distance to the exercise facility. Future research can investigate the distance to a facility to understand the size of a "catchment" area, within which residents are more likely to use the facility.

\section{Conclusions}

This study found that the construction of a new exercise facility in a regional city in Japan did not generate an increase in community-level PA during the study period. However, significant improvement in awareness of recreational facilities was observed in the intervention site, suggesting that the new facility may have raised awareness of PA opportunities, which could over a period help some people to initiate PA. A sustained community-level effort to promote PA, possibly including social components, and a further tracking of residents' PA are needed to take advantage of the new exercise facility and to assess its long-term impact.

\section{Additional file}

Additional file 1: Table S1. Differences in outcome changes from baseline to follow-up between the sites (men). Table S2. Differences in outcome changes from baseline to follow-up between the sites (women).
Table S3. Differences in outcome changes from baseline to follow-up between the sites (aged 30-59 years). Table S4. Differences in outcome changes from baseline to follow-up between the sites (aged 60-74 years). (DOCX $20 \mathrm{~kb}$ )

\section{Abbreviations}

MVPA: Moderate-to-vigorous intensity physical activity; NHPC: Nagaizumi Health Promotion Center; PA: Physical activity

\section{Acknowledgements}

The authors would like to thank the staff of the Health Promotion Division of Nagaizumi and Oiso for their cooperation.

\section{Authors' contributions}

AK, MM, and TA coordinated with the local governments of Nagaizumi and Oiso in setting up the study, developed study design, and implemented data collection. AK conducted data analysis. BJS and TS assisted with data analysis and interpretation. AK, BJS, and TS drafted the manuscript. All authors critically reviewed the manuscript and read and approved the final manuscript.

\section{Funding}

This study was funded by the Japan Society for the Promotion of Science (Grants-in-Aid for Scientific Research, \# JP24300232). The manuscript was written when the lead author was visiting Australian Catholic University, using the financial support from Tokai University. The funders had no role in study design, data collection and analysis, decision to publish, or preparation of the manuscript.

\section{Availability of data and materials}

The datasets used and/or analyzed for the current study are not publicly available due to data sharing not being approved by Nagaizumi and Oiso local governments, but are available from the corresponding author if approved by these local governments.

\section{Ethics approval and consent to participate}

Ethical approval was obtained from the Waseda University Ethics Committee prior to the study (No. 2012-179, 05/10/2012). We obtained informed written consent from participants who agreed to participate in the study.

\section{Consent for publication}

Not applicable.

\section{Competing interests}

The authors declare that they have no competing interests.

\section{Author details}

${ }^{1}$ School of Physical Education, Tokai University, 4-1-1 Kitakaname,

Hiratsuka-shi, Kanagawa 259-1292, Japan. ${ }^{2}$ Mary MacKillop Institute for Health Research, Australian Catholic University, 215 Spring St, Melbourne, VIC 3000

Australia. ${ }^{3}$ School of Public Health and Preventive Medicine, Monash

University, 553 St Kilda Road, Melbourne, VIC 3004, Australia. ${ }^{4}$ Sydney School of Public Health, University of Sydney, Edward Ford Building (A27) Fisher Road, Sydney, NSW 2006, Australia. ${ }^{5}$ Centre for Urban Transitions, Swinburne University of Technology, EW Building, Hawthorn, VIC 3122, Australia. ${ }^{6}$ Meiji Yasuda Life Foundation of Health and Welfare, Physical Fitness Research Institute, 150 Tobukimachi, Hachioji-shi, Tokyo 192-0001, Japan.

Received: 6 November 2018 Accepted: 10 June 2019

Published online: 18 June 2019

\section{References}

1. World Health Organization. Global recommendations on physical activity for health. 2010. http://apps.who.int/iris/bitstream/handle/10665/44399/ 9789241599979 eng.pdf. Accessed 12 Sept 2018.

2. Bauman A, Bull F, Chey T, Craig CL, Ainsworth BE, Sallis JF, et al. The international prevalence study on physical activity: results from 20 countries. Int J Behav Nutr Phys Act. 2009;6:21. 
3. Ministry of Health, Labour and Welfare of Japan. The National Health and Nutrition Survey 2018. https://www.mhlw.go.jp/content/10904750/ 000351576.pdf. Accessed 25 Apr 2019.

4. Marcus BH, Dubbert PM, Forsyth LH, McKenzie TL, Stone EJ, Dunn AL, et al. Physical activity behavior change: issues in adoption and maintenance. Health Psychol. 2000;19(1s):32-41.

5. Schilling JM, Giles-Corti B, Sallis JF. Connecting active living research and public policy: transdisciplinary research and policy interventions to increase physical activity. J Public Health Policy. 2009;30(Suppl 1):S1-15.

6. Sallis JF, Owen N. Ecological models of health behavior. In: Glanz K, Rimer BK, Viswanath K, editors. Health behavior theory: theory, research, and practice. 5th ed. San Francisco: Jossey-Bass; 2015. p. 43-64.

7. Haggis C, Sims-Gould J, Winters M, Gutteridge K, McKay HA. Sustained impact of community-based physical activity interventions: key elements for success. BMC Public Health. 2013:13:892.

8. Baker PR, Francis DP, Soares J, Weightman AL, Foster C. Community wide interventions for increasing physical activity. Cochrane Database Syst Rev. 2015;1:Cd008366.

9. Kaczynski AT, Henderson KA. Environmental correlates of physical activity: a review of evidence about parks and recreation. Leisure Sci. 2007;29:315-54.

10. Lee SA, Ju YJ, Lee JE, Hyun IS, Nam JY, Han KT, et al. The relationship between sports facility accessibility and physical activity among Korean adults. BMC Public Health. 2016;16:893.

11. Jansen M, Kamphuis CBM, Pierik FH, Ettema DF, Dijst MJ. Neighborhoodbased PA and its environmental correlates: a GIS- and GPS based crosssectional study in the Netherlands. BMC Public Health. 2018;18(1):233.

12. Veitch J, Salmon J, Crawford D, Abbott G, Giles-Corti B, Carver A, et al. The REVAMP natural experiment study: the impact of a play-scape installation on park visitation and park-based physical activity. Int J Behav Nutr Phys Act. 2018;15(1):10

13. Cohen DA, Han B, Isacoff J, Shulaker B, Williamson S, Marsh T, et al. Impact of park renovations on park use and park-based physical activity. J Phys Act Health. 2015;12(2):289-95.

14. Halonen Jl, Stenholm S, Kivimaki M, Subramanian SV, Kawachi I, et al. Is change in availability of sports facilities associated with change in physical activity? A prospective cohort study. Prev Med. 2015:73:10-4.

15. Karmeniemi M, Lankila T, Ikaheimo T, Koivumaa-Honkanen H, Korpelainen R. The built environment as a determinant of physical dctivity: a systematic review of longitudinal studies and natural experiments. Ann Behav Med. 2018;52(3):239-51.

16. Inoue S, Ohya Y, Tudor-Locke C, Tanaka S, Yoshiike N, Shimomitsu T. Time trends for step-determined physical activity among Japanese adults. Med Sci Sports Exerc. 2011;43(10):1913-9.

17. Matsushita M, Kubota A, Arao T. Development of a population strategy for promoting physical activity in local community: study profile. Lifelong Sports. 2014;11(1):45-53 In Japanese.

18. World Health Organization. Preventing chronic disease: a vital investment 2005. http://www.who.int/chp/chronic_disease_report/part1/en/. Accessed 12 Sept 2018.

19. Murase N, Katsamura T, Ueda C, Inoue S, Shimomitsu T. Validity and reliability of Japanese version of international physical activity questionnaire. J Health Welfare Stat. 2002;49:1-9 In Japanese.

20. Ministry of Health, Labour and Welfare of Japan. Revising physical activity guidelines for health promotion. 2013. https://www.mhlw.go.jp/content/ 000306883.pdf. Accessed 12 Sept 2018.

21. Saito $Y$, Oguma $Y$, Tanaka A, Kamada M, Inoue S, Inaji J, et al. Community-wide physical activity intervention based on the Japanese physical activity guidelines for adults: a non-randomized controlled trial. Prev Med. 2018;107:61-8.

22. Snyder C, Anderson G. Do quality improvement organizations improve the quality of hospital care for Medicare beneficiaries? JAMA. 2005;293(23):2900-7.

23. Kamada M, Kitayuguchi J, Abe T, Taguri M, Inoue S, Ishikawa Y, et al. Community-wide promotion of physical activity in middle-aged and older Japanese: a 3-year evaluation of a cluster randomized trial. Int J Behav Nutr Phys Act. 2015;12:82

24. Phillips G, Bottomley C, Schmidt E, Tobi P, Lais S, Yu G, et al. Measures of exposure to the well London Phase-1 intervention and their association with health well-being and social outcomes. J Epidemiol Community Health. 2014;68(7):597-605.

25. Solomon E, Rees T, Ukoumunne OC, Metcalf B, Hillsdon M. The Devon active villages evaluation (DAVE) trial of a community-level physical activity intervention in rural south-West England: a stepped wedge cluster randomised controlled trial. Int J Behav Nutr Phys Act. 2014;11:94.

26. Cohen DA, Golinelli D, Williamson S, Sehgal A, Marsh T, McKenzie TL. Effects of park improvements on park use and physical activity: policy and programming implications. Am J Prev Med. 2009;37(6):475-80.

27. Tester J, Baker R. Making the playfields even: evaluating the impact of an environmental intervention on park use and physical activity. Prev Med. 2009;48(4):316-20.

28. Ministry of Health, Labour and Welfare of Japan. National Health and nutrition survey 2016. 2016. https://www.mhlw.go.jp/bunya/kenkou/eiyou/ dl/h28-houkoku.pdf. Accessed 12 Sept 2018.

29. De Bourdeaudhuij I, Teixeira PJ, Cardon G, Deforche B. Environmental and psychosocial correlates of physical activity in Portuguese and Belgian adults. Public Health Nutr. 2005:8(7):886-95.

30. Mesters I, Wahl S, Van Keulen HM. Socio-demographic, medical and socialcognitive correlates of physical activity behavior among older adults (45-70 years): a cross-sectional study. BMC Public Health. 2014;14:647.

31. Shibata A, Oka K, Harada K, Nakamura Y, Muraoka I. Psychological, social, and environmental factors to meeting physical activity recommendations among Japanese adults. Int J Behav Nutr Phys Act. 2009:6:60.

32. Marshall SJ, Biddle SJ. The transtheoretical model of behavior change: a meta- analysis of applications to physical activity and exercise. Ann Behav Med. 2001;23(4):229-4

\section{Publisher's Note}

Springer Nature remains neutral with regard to jurisdictional claims in published maps and institutional affiliations.
Ready to submit your research? Choose BMC and benefit from:

- fast, convenient online submission

- thorough peer review by experienced researchers in your field

- rapid publication on acceptance

- support for research data, including large and complex data types

- gold Open Access which fosters wider collaboration and increased citations

- maximum visibility for your research: over $100 \mathrm{M}$ website views per year

At BMC, research is always in progress.

Learn more biomedcentral.com/submissions 